Original Article

\title{
Comparison of postural sway depending on balance pad type
}

\author{
DongGeon Lee, PT, MSc ${ }^{1)}$, HaNa Kim, PT, BSc ${ }^{2)}$, HyunJi An, PT, BSc ${ }^{2)}$, \\ JiEun JAng, PT, BSc ${ }^{2}$, SoungKyun Hong, PT, MSc ${ }^{1}$, SunHye Jung, PT, MSc ${ }^{1)}$, \\ Kyeongbong Lee, PT, PhD ${ }^{3)}$, Myong-Ryol Choi, PT, PhD ${ }^{4}$, Kyung-Hee Lee, PT, PhD ${ }^{5}$, \\ GyuChang LeE, PT, PhD ${ }^{2 *}$ \\ 1) Department of Physical Therapy, Graduate School of Kyungnam University, Republic of Korea \\ 2) Department of Physical Therapy, Kyungnam University: 7 Kyungnamdaehak-ro, Masanhappo-gu, \\ Changwon-si, Gyeongsangnam-do 51767, Republic of Korea \\ 3) Physical and Rehabilitation Medicine, Samsung Medical Center, Republic of Korea \\ 4) Department of Rehabilitation Medicine, Dongguk University Ilsan Medical Center, Republic of \\ Korea \\ 5) Department of Physical Therapy, Dongnam Health University, Republic of Korea
}

\begin{abstract}
Purpose] The purpose of the present study was to compare the postural sway of healthy adults standing on different types of balance pads. [Subjects and Methods] Nine healthy adults participated in this study. Postural body sway was measured while participants were standing on four different types of balance pads: Balancepad Elite (BE), Aero-Step XL (AS), Dynair Ballkissen Senso (DBS), and Dynair Ballkissen XXL Meditation and Yoga (DBMY). A Wii Balance Board interfaced with Balancia software was used to measure postural body sway. [Results] In the sway velocity, sway path length, and sway area, no significant differences were found between baseline conditions (participants were standing on the floor with no balance pad) and the use of the BE or AS. However, significant increases in all parameters were found comparing baseline conditions to the use of either Dynair balance pad. Furthermore, the use of either Dynair balance pad significantly increased postural sway compared to both the $\mathrm{BE}$ and the AS. [Conclusion] These findings suggest that the DBS and DBMY balance pads may serve as superior tools for providing unstable condition for balance training than the BE and the AS balance pads.

Key words: Balance pad, Postural sway, Balance training
\end{abstract}

(This article was submitted Sep. 27, 2017, and was accepted Nov. 15, 2017)

\section{INTRODUCTION}

A sensory system located in structures of the inner ear that registers the orientation of the heada sensory system located in structures of the inner ear that registers the orientation of the heada sensory system located in structures of the inner ear that registers the orientation of the headUnlike quadrapedal mammals, humans require diverse abilities to maintain equilibrium in a bipedal stance ${ }^{1)}$. Equilibrium is a sensory system that registers the orientation head and a balance between several different influences or aspects of situation ${ }^{2}$. Thus the ability to maintain equilibrium is the functional foundation for mobility and enables humans to enjoy functional independence throughout their life $\operatorname{span}^{3}$ ). Balance is defined as minimizing body sway induced by external stimuli and maintaining the body's center of gravity within the base of support ${ }^{4}$. So, the standing Balance is also important predictor of the safe performance of gait and functional activities, an extensive range of programs ${ }^{5)}$. Balance involves both static balance and dynamic balance. Static balance refers to the ability of a body to maintain its center

*Corresponding author. GyuChang Lee (E-mail: leegc76@kyungnam.ac.kr)

(C2018 The Society of Physical Therapy Science. Published by IPEC Inc.

(c) (1) $\odot$ This is an open-access article distributed under the terms of the Creative Commons Attribution Non-Commercial No Deriva-

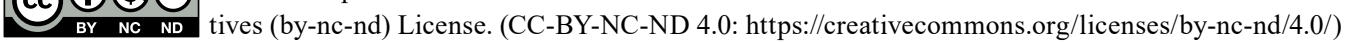


of gravity within the base of support at rest, whereas dynamic balance refers to the ability of a body to maintain its center of gravity within the base of support in motion ${ }^{6}$. The proprioceptive, cutaneous, visual, and vestibular systems contribute to control of posture ${ }^{7)}$ which involves proper interactions with the information received from these systems at a high level ${ }^{8)}$. Proprioception is a component of the somatosensory system and involves the ability to perceive the movement and spatial orientation of the body by processing afferent information from stimuli within the body itself (e.g., from proprioceptors in joints, muscles, and tendons $)^{9}$ ).

Impaired balance has been reported to substantially limit the ability to maintain a standing posture ${ }^{10)}$. Even with a proper posture, loss of balance control will cause unbalanced loads. Chronic exposure to unbalanced loads may lead to structural changes in the musculoskeletal system ${ }^{11)}$. Therefore, efficient therapeutic approaches based on the appropriate assessment and training of balance are required ${ }^{12}$. Furthermore, postural instability in older adults leads to injuries through falls, limits independence, reduces the quality of life, and can even lead to death ${ }^{13)}$. Therefore, it is critical to provide methods to maintain and improve balance and control of posture, especially in older adults.

Balance training is an effective means to improve proxies of static/dynamic steady-state, proactive, and reactive balance as well as performance in balance test in healthy person ${ }^{14)}$. So many studies have reported on various interventions to improve balance control. Hippotherapy ${ }^{15)}$, Kung-fu swimming ${ }^{16)}$, Tai Chi Chuan ${ }^{17}$, and the Wii Fit video game system ${ }^{18)}$ have all been reported to be effective at improving balance. In addition, training programs using balance pads (e.g., wobble boards, sponge pads, ethylene vinyl acetate pads, memory foams, and Aero-step boards, have also been reported to be effective $^{1,19,20)}$. Above all, balance pads are an easy-to-use training tool intended to improve balance performance ${ }^{21)}$. There are a wide variety of types of balance pads, where the choice of balance pad type controls the level of difficulty one experiences when performing a range of movements during balance exercise ${ }^{22}$. Accordingly, it has been demonstrated that the type of balance pad used can significantly affect postural sway ${ }^{23,24)}$. Many previous studies have used balance pads as intervention tools to improve balance control. However, there is a paucity of data on the criteria to use in selecting the proper type of balance pad for specific clinical applications or patient types.

Thus, there exists a need to compare the postural sway of users on different types of balance pads to establish criteria for the proper selection of balance pads for individuals with problematic conditions and identify what type of pad use has a greater impact on the patient who has impaired balance for proper balance control. To address this need, we compared the sway path length, sway velocity, and sway area on different types of balance pads to use as a reference for the selection of the proper type of balance pad to achieve specific conditions in balance training.

\section{SUBJECTS AND METHODS}

To recruit participants, a public notice was posted on the bulletin board at the University stating the study objective and methods. Of the 13 volunteers, 9 were screened according to the following selection criteria: 1) healthy women aged 20-29 years, 2) no musculoskeletal or nervous system disease(s), 3) no congenital abnormality or inflammatory disease(s) in the lower extremities, 4) no open wounds, and 5) the ability to perform movements as instructed by the researcher. The participants were 9 female, with average 22.0 (0.50) years old, $160.44(5.57) \mathrm{cm}$ in height, and $52.56(5.50) \mathrm{kg}$ in weight.

This study was approved by the Institutional Review Board of Kyungnam University. Written consent was obtained from all participants prior to the commencement of this study.

This was a comparative cross-sectional study. The general information including age, height, and weight of each participant were collected. Before measuring postural body sway on each balance pad, baseline conditions for each participant were established by measuring postural body sway in a static standing position without balance pad. And then, the postural body sway was measured on each of the four types of balance pads in a random order chosen by each participant. The following balance pads were used in this study: A) Balance-pad Elite (Alcan airex AG, Sins, Switzerland), a rectangular blue sponge pad measuring $50 \mathrm{~cm}(\mathrm{~W}) \times 41 \mathrm{~cm}(\mathrm{~L}) \times 6 \mathrm{~cm}(\mathrm{H})$; B) Aero-Step XL (Togu, Prien-Bachham, Germany), a blue latex pad consisting of two conjoined air-filled hemispherical segments with bumpy surfaces measuring $51 \mathrm{~cm}(\mathrm{~W}) \times 37 \mathrm{~cm}(\mathrm{~L}) \times 8 \mathrm{~cm}$ (H); C) Dynair Ballkissen Senso (Togu), an air-filled circular pad made of soft green velvet with a bumpy surface measuring $33 \mathrm{~cm}$ in diameter and $7 \mathrm{~cm}$ in height; and D) Dynair Ballkissen XXL Meditation and Yoga (Togu), an air-filled circular pad made of soft red velvet with a bumpy surface measuring $50 \mathrm{~cm}$ in diameter and $14 \mathrm{~cm}$ in height (Fig. 1).

The types of pads were chosen as the most used pads in clinical practice and the characteristics of each pad are as follows:

A) Balance-pad Elite is the most traditional type of pad and it provides a sense of stability with the square structure. B) Aero-Step XL divided the pressure-sensitive part of both feet to make the same environment on both feet. Because it is divided into two parts, so it is used for walking in place balance training before increasing walking balance. The basic type D) Dynair Ballkissen XXL Meditation and Yoga is used mainly for one-foot strength or balance exercise. And except for the bumpy surface, C) Dynair Ballkissen Senso is similar to D) Dynair Ballkissen XXL Meditation and Yoga. So it is used for sensor stimulation for people who need more sensitive activation.

To establish baseline conditions, the participants were instructed to place both feet shoulder-width apart directly on the force plate and stand with both arms lowered at their sides ${ }^{25}$. Subsequently, each participant was asked to repeat the same procedure while standing on each type of balance pad placed on the surface of the force plate. To minimize postural sway due to unsteady gaze during measurements, the participants were asked to look at a sign marked at eye level at a distance of 

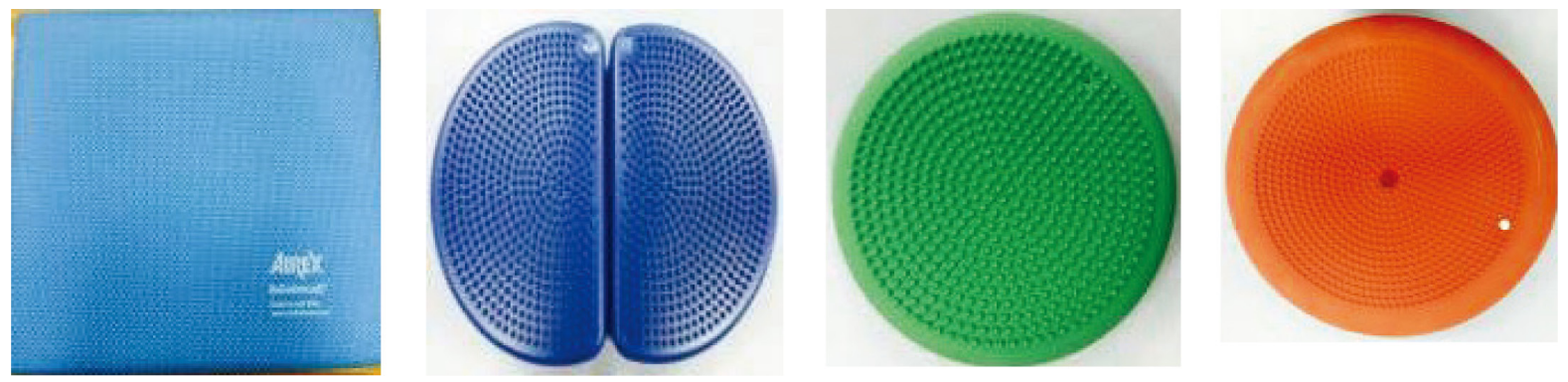

Fig. 1. Balance pads: (A) Balance-pad Elite, (B) Aero-Step XL, (C) Dynair Ballkissen Senso, (D) Dynair Ballkissen XXL Meditation and Yoga.

$2 \mathrm{~m}$. Each participant was given 10 seconds for practice and adaptation on each balance pad prior to measurement. Postural sway was then measured twice for 30 seconds. The velocity, path length, and area of postural sway were recorded. Mean values were calculated for each parameter by averaging the data collected from each of the two measurements. Participants were given a 30-second break between measurements on each type of balance pad, and a 1-minute break before switching to a different balance pad.

The experiment was performed in a quiet and spacious room in the evening to minimize the influence of external environment. To prevent the risk of fall on the balance pads, a research assistant was positioned behind the participants to supervise the process. Another well-trained research assistant performed measurements using the force plate.

To measure the postural body sway, a Nintendo Wii Balance Board (WBB) interfaced with Balancia software version 2.0 (Mintosys, Seoul, South Korea) was used. The WBB was used as a device comparable to force platforms commonly utilized to quantify gait, balance, and other biomechanical parameters ${ }^{26,27)}$. To collect the postural body sway data, the Balancia software was used to extract and process data from the WBB. The WBB contains four load cells at each of its corners that are used to collect center of pressure (COP) data. The collected data is then transmitted to a computer unit connected via Bluetooth. The data was sampled at $50 \mathrm{~Hz}$ and filtered by a 4th order Butterworth low pass filter with a cut-off frequency of $12 \mathrm{~Hz}$. The intraclass correlation coefficient (ICC) of the inter-rater reliability of this tool was ICC $=0.79-0.89$, while the intra-rater reliability was $\mathrm{ICC}=0.70-0.92$. The concurrent validity reported was $\mathrm{ICC}=0.73-0.87 .27$

SPSS 18.0 software was used for all statistical analyses. Descriptive statistics were used to determine the general characteristics of the participants. One-way ANOVA and post-hoc test with a statistical significance level of $\alpha=0.05$ were used to compare the postural sway parameters on different types of balance pads.

\section{RESULTS}

The analysis of postural sway velocity, sway path length, and sway area on each type of balance pad highlighted several key differences (Table 1). Compared to baseline conditions, the use of the Balance-pad Elite or the Aero-Step XL showed no significant differences in the velocity, path length, or area of postural body sway, whereas the use of either the Dynair Ballkissen Senso or the Dynair Ballkissen XXL Meditation and Yoga balance pads significantly increased postural sway compared to baseline conditions $(\mathrm{p}<0.05)$. Compared with either the Balance-pad Elite or the Aero-Step XL, both Dynair balance pads showed significant increases in all measured parameters $(p<0.05)$. However, no significant differences were found between the Balance-pad Elite and Aero Step XL or between the Dynair Ballkissen Senso and Dynair Ballkissen XXL Meditation and Yoga balance pads.

\section{DISCUSSION}

The present study investigated how the type of balance pad used in balance control affects postural sway. Balance, or postural control, refers to complex motor functions involving sensory feedback, movement strategies, orientation in space, biomechanical constraints, and cognition ${ }^{28)}$. Balance control in healthy adults involves processing afferent information from cutaneous mechanoreceptors on the soles of the feet ${ }^{29}$. The mechanoreceptors on the soles of the feet provide information about surface contact pressures ${ }^{30)}$, and balance control is mediated by feedback and feedforward mechanisms coordinated by the sensory and motor systems ${ }^{31)}$.

McIlroy et al. ${ }^{32)}$ reported that increased postural sway on an unstable surface resulted in a postural reflex characterized by increased afferent input from the cutaneous receptors in the soles of the feet ${ }^{32}$. Balance on an unstable surface is controlled by adjusting the contact points of the feet and shifting the body's center of gravity ${ }^{33)}$. Since unstable surfaces increase postural reflex activity, they are more effective for improving muscle activity than stable surfaces ${ }^{34,35)}$. Behm et al. reported balance training on unstable surfaces enhanced musculoskeletal functions in adults ${ }^{36)}$. Similarly, Shumway-Cook and Wool- 
Table 1. Comparison of postural sway velocity, sway path length, and sway area depending on each type of balance pad

\begin{tabular}{|c|c|c|c|c|c|c|}
\hline & $\begin{array}{l}\text { Baseline condi- } \\
\text { tion }\end{array}$ & $\begin{array}{l}\text { Use of Balance- } \\
\text { pad Elite }\end{array}$ & $\begin{array}{c}\text { Use of Aero-Step } \\
\text { XL }\end{array}$ & $\begin{array}{c}\text { Use of Dynair } \\
\text { Ballkissen Senso }\end{array}$ & $\begin{array}{c}\text { Use of Dynair } \\
\text { Ballkissen XXL } \\
\text { Meditation and Yoga }\end{array}$ & $\mathrm{p}$ \\
\hline Sway velocity $(\mathrm{cm} / \mathrm{s})$ & $2.40(0.30)$ & $2.72(0.30)$ & $3.05(0.31)$ & $4.99(0.83)^{*, \dagger, t}$ & $4.91(0.74)^{*}, \dagger,+$ & 0.000 \\
\hline Sway path length $(\mathrm{cm})$ & $72.10(8.99)$ & $81.54(8.94)$ & $91.53(9.16)$ & $149.64(25.02)^{*, \dagger, \$}$ & $147.20(22.27)^{*,+, *}$ & 0.000 \\
\hline Sway area $\left(\mathrm{cm}^{2}\right)$ & $1.06(0.42)$ & $3.65(0.67)$ & $5.44(1.56)$ & $15.40(3.07)^{*}, \dot{\dagger},+$ & $17.03(7.35)^{*, \dagger, \$}$ & 0.000 \\
\hline
\end{tabular}

Date are mean (SD).

*Significant differences between baseline condition and the Dynair Ballkissen Senso or the Dynair Ballkissen XXL Meditation and Yoga; ${ }^{\dagger}$ Significant differences between the Balance-pad Elite and the Dynair Ballkissen Senso or the Dynair Ballkissen XXL Meditation and Yoga; ${ }^{*}$ Significant differences between the Aero-Step XL and the Dynair Ballkissen Senso or the Dynair Ballkissen XXL Meditation and Yoga.

lacott reported unstable surfaces were effective for improving foot proprioception ${ }^{37)}$.

Blance training is regaining a normal functional level of neuromuscular control ${ }^{38)}$. Balance training may influence afferent input, result in changes in the sensory cortex, and might augment motoneuron pool excitability ${ }^{39)}$. Furthermore, balance training effectively reduces the risk of sustaining an musculoskeletal sprain ${ }^{40)}$. However, to make a clear statement on how to progress during balance training, however, research is lacking on the effect of pad types on postural sway or muscle activation. So, to evaluate the effect of balance pad type on postural sway used several type in this study.

The Balance-pad Elite and Aero Step XL balance pads used in this study were relatively firm and stable enough for participants to maintain balance easily while standing. By contrast, the Dynair Ballkissen Senso and Dynair Ballkissen XXL Meditation and Yoga balance pads were filled with air and not as firm as the Balance-pad Elite and Aero Step XL balance pads. Consequently, the Dynair balance pads were more unstable and made it more difficult for participants to maintain balance control. Thus, the postural body sway proved significantly greater on the Dynair balance pads than the Balance-pad Elite and Aero Step XL balance pads. This finding suggested that the Dynair Ballkissen Senso and Dynair Ballkissen XXL Meditation and Yoga could be more effective for improving balance control by providing unstable surfaces for balance training.

In agreement with this conclusion, a previous study compared postural balance in participants standing on firm versus soft foams, and reported standing on the soft foam increased the likelihood of contacting the hard surface beneath the balance pad. In turn, this contact enabled participants to use the mechanoreceptors on the soles of their feet to sense the hard surface beneath the foam to receive more sensory information. Therefore, balance training on a soft, unstable surface is more likely to induce increased sensory feedback for proprioceptive stimulation due to unstable movements than balance training on a firm, stable surface. This increased sensory feedback exerts effects on sensing body orientation and helps recover balance through corrective body movements ${ }^{23}$. In addition to balance pad firmness, Corbin et al. suggested the surface texture of balance pads could affect postural sway ${ }^{24)}$. Balance pads with a range of shapes and surface textures provide participants with different sensory inputs than smooth surfaces. The attribution of these differences in sensory feedback to the different shapes and surface textures of balance pads are further supported by our findings. It is also important to note that no significant differences in postural sway were found between the Dynair balance pads in our study. These balance pads differed in size only, not in surface texture or shape. This finding suggests that balance pad size does affect postural sway in the same manner that balance pad firmness, shape, and surface texture do. Because, as the size of pad increases, increased visual stability and as the margin of footprint increases, psychological stability also increased.

A previous study comparing a foam rubber exercise group with a stable surface exercise group and control group for 4 months in elderly people found the foam rubber exercise to enhance improvements in balance control ${ }^{41)}$. This study demonstrated that the stable surface required two additional months of balance training to achieve the same enhancement in balance performance yielded by the foam rubber pad. In comparison to an untrained control group, both the foam rubber pad and the stable surface showed improvements in lower extremity muscle strength. However, there were no significant differences in muscle strength between participants using the foam rubber pad and the stable surface ${ }^{41}$ ). In another study, Lee et al. studied the effects of balance training on an Aero-step board and reported significant improvements in both the overall and anteroposterior stability indices after training ${ }^{42}$. This finding was attributable to the use of Aero-step, where the dorsiflexion and plantarflexion of the ankle joint substantially stimulated the Golgi tendon organs and muscle spindles ${ }^{42}$. The two studies mentioned above used the same balance pads as those used in the present study: the Airex's Balance-pad Elite and TOGU's Aero-step XL. However, the present study found no significant differences in postural sway between baseline conditions where a stable, flat surface was provided and the use of either the Balance-pad Elite or Aero-step XL. This finding is attributable to the fact that these stable surfaces were less deformable than either Dynair balance pad. However, the aforementioned studies used Balance-pad Elite and Aero-step XL as balance training tools in a longitudinal study where effects were recorded over time, whereas the present cross-sectional study focused on comparing the extent of postural body sway depending on the type of balance pad used at a defined point in time. This difference in study design may account for the differences 
between previous and present findings. Thus, these previous studies demonstrated that the Balance-pad Elite and Aero-step XL may prove more effective for improving the balance control than flat, firm surfaces if they are used as training tools for an extended period. In contrast, our findings serve as a reference for formulating a balance exercise protocol with the proper choice of balance pad type to offer different levels of difficulty tailored to varying levels of balance control performance.

Balance pads are balance training tools designed to improve balance performance and, in agreement with our findings, varying the type of balance pad used provides a convenient method for controlling balance training difficulty ${ }^{43}$, 44). For example, in older adults or in individuals with neurological deficits who demonstrate poor balance performance, it may be more appropriate to use firm, stable balance pads and then to apply increasingly difficult tasks. Alternatively, gradual progression to more unstable balance pads could be used as a method to increase the level of difficulty. In addition, performing increasingly difficult tasks on unstable balance pads would be more beneficial than on stable surfaces to further improve balance control.

It is necessary to note the limitations of this study. First, the sample size was small and consisted of only healthy women in their 20s, which potentially limits the generalizability of these findings. In addition, this study investigated the differences in postural body sway on different types of balance pads and did not investigate how the type of balance pad affected the improvement of balance control. These limitations motivate further studies concerning the effects of different types of balance pads on the improvement of balance control.

Conflict of interest

The authors declare no conflicts of interest.

\section{REFERENCES}

1) Cimadoro G, Paizis C, Alberti G, et al.: Effects of different unstable supports on EMG activity and balance. Neurosci Lett, 2013, 548: 228-232. [Medline] [CrossRef]

2) Collins Cobuild Advanced Learner's English Dictionary: 6th ed. HarperCollins Publisher, 2009.

3) Yim-Chiplis PK, Talbot LA: Defining and measuring balance in adults. Biol Res Nurs, 2000, 1: 321-331. [Medline] [CrossRef]

4) Berg K, Norman KE: Functional assessment of balance and gait. Clin Geriatr Med, 1996, 12: 705-723. [Medline]

5) Sung J, Choi S, Kim H, et al.: Feasibility of rehabilitation training with a newly developed, portable, gait assistive robot for balance function in hemiplegic patients. Ann Rehabil Med, 2017, 41: 178-187. [Medline] [CrossRef]

6) O'Sullivan SB, Schmitz TJ, Fulk G: Physical rehabilitation, 5th ed. FA Davis. 2013.

7) Peterka RJ: Sensorimotor integration in human postural control. J Neurophysiol, 2002, 88: 1097-1118. [Medline]

8) Maurer C, Mergner T, Bolha B, et al.: Vestibular, visual, and somatosensory contributions to human control of upright stance. Neurosci Lett, 2000, 281: 99-102. [Medline] [CrossRef]

9) Lephart SM, Fu FH: Proprioception and neuromuscular control in joint stability. Hillsdale: Human Kinetics, 2000.

10) Schmitt K, Kressig RW: [Mobility and balance]. Ther Umsch, 2008, 65: 421-426 (In German). [Medline] [CrossRef]

11) Norkin CC, Levangi PK: Joint structure \& function: a comprehensive analysis, 2nd ed. FA Davis, 1992.

12) Song JW, Kim JM, Cheong YS, et al.: Balance assessment in subacute stroke patients using the balance control trainer (BalPro). Ann Rehabil Med, 2017, 41: 188-196. [Medline] [CrossRef]

13) Buracchio TJ, Mattek NC, Dodge HH, et al.: Executive function predicts risk of falls in older adults without balance impairment. BMC Geriatr, 2011 , 11: 74. [Medline] [CrossRef]

14) Lesinski M, Hortobágyi T, Muehlbauer T, et al.: Effects of balance training on balance performance in healthy older adults: a systematic review and metaanalysis. Sports Med, 2015, 45: 1721-1738. [Medline] [CrossRef]

15) Bronson C, Brewerton K, Ong J, et al.: Does hippotherapy improve balance in persons with multiple sclerosis: a systematic review. Eur J Phys Rehabil Med, 2010, 46: 347-353. [Medline]

16) Baccouch R, Rebai H, Sahli S: Kung-fu versus swimming training and the effects on balance abilities in young adolescents. Phys Ther Sport, 2015, 16: 349-354. [Medline] [CrossRef]

17) Rahal MA, Alonso AC, Andrusaitis FR, et al.: Analysis of static and dynamic balance in healthy elderly practitioners of Tai Chi Chuan versus ballroom dancing. Clinics (Sao Paulo), 2015, 70: 157-161. [Medline] [CrossRef]

18) Mhatre PV, Vilares I, Stibb SM, et al.: Wii Fit balance board playing improves balance and gait in Parkinson disease. PM R, 2013, 5: 769-777. [Medline] [CrossRef]

19) Chaikeeree N, Saengsirisuwan V, Chinsongkram B, et al.: Interaction of age and foam types used in Clinical Test for Sensory Interaction and Balance (CTSIB). Gait Posture, 2015, 41: 313-315. [Medline] [CrossRef]

20) Nam CW, Kim K, Lee HY: The influence of exercise on an unstable surface on the physical function and muscle strength of patients with osteoarthritis of the knee. J Phys Ther Sci, 2014, 26: 1609-1612. [Medline] [CrossRef]

21) Muehlbauer T, Roth R, Bopp M, et al.: An exercise sequence for progression in balance training. J Strength Cond Res, 2012, 26: 568-574. [Medline] [CrossRef]

22) Morioka S, Fujita H, Hiyamizu M, et al.: Effects of plantar perception training on standing posture balance in the old old and the very old living in nursing facilities: a randomized controlled trial. Clin Rehabil, 2011, 25: 1011-1020. [Medline] [CrossRef]

23) Patel M, Fransson PA, Lush D, et al.: The effect of foam surface properties on postural stability assessment while standing. Gait Posture, $2008,28:$ 649-656. [Medline] [CrossRef]

24) Corbin DM, Hart JM, McKeon PO, et al.: The effect of textured insoles on postural control in double and single limb stance. J Sport Rehabil, 2007, 16: 363-372. [Medline] [CrossRef] 
25) Laufer Y, Sivan D, Schwarzmann R, et al.: Standing balance and functional recovery of patients with right and left hemiparesis in the early stages of rehabilitation. Neurorehabil Neural Repair, 2003, 17: 207-213. [Medline] [CrossRef]

26) Haas BM, Burden AM: Validity of weight distribution and sway measurements of the Balance Performance Monitor. Physiother Res Int, 2000, 5: 19-32. [Medline] [CrossRef]

27) Park DS, Lee G: Validity and reliability of balance assessment software using the Nintendo Wii balance board: usability and validation. J Neuroeng Rehabil, 2014, 11: 99. [Medline] [CrossRef]

28) Horak FB: Postural orientation and equilibrium: what do we need to know about neural control of balance to prevent falls? Age Ageing, 2006, 35: ii7-iil1. [Medline] [CrossRef]

29) Magnusson M, Enbom H, Johansson R, et al.: Significance of pressor input from the human feet in anterior-posterior postural control. The effect of hypothermia on vibration-induced body-sway. Acta Otolaryngol, 1990, 110: 182-188. [Medline] [CrossRef]

30) Vallbo AB, Johansson RS: Properties of cutaneous mechanoreceptors in the human hand related to touch sensation. Hum Neurobiol, 1984, 3: 3-14. [Medline]

31) Fransson PA, Kristinsdottir EK, Hafström A, et al.: Balance control and adaptation during vibratory perturbations in middle-aged and elderly humans. Eur J Appl Physiol, 2004, 91: 595-603. [Medline] [CrossRef]

32) McIlroy WE, Bishop DC, Staines WR, et al.: Modulation of afferent inflow during the control of balancing tasks using the lower limbs. Brain Res, 2003, 961 : 73-80. [Medline] [CrossRef]

33) Ivanenko YP, Levik YS, Talis VL, et al.: Human equilibrium on unstable support: the importance of feet-support interaction. Neurosci Lett, 1997, 235: 109-112. [Medline] [CrossRef]

34) Anderson K, Behm DG: Trunk muscle activity increases with unstable squat movements. Can J Appl Physiol, 2005, 30: 33-45. [Medline] [CrossRef]

35) Behm DG, Leonard AM, Young WB, et al.: Trunk muscle electromyographic activity with unstable and unilateral exercises. J Strength Cond Res, 2005, 19: 193-201. [Medline]

36) Behm DG, Colado JC, Colado JC: Instability resistance training across the exercise continuum. Sports Health, 2013, 5: 500-503. [Medline] [CrossRef]

37) Shumsway-Cook A, Woollacott MH: Motor control: translating research into clinical practice, 3rd ed. Philadelphia: Lippincott, Williams \& Wilkins, 2007.

38) Ashton-Miller JA, Wojtys EM, Huston LJ, et al.: Can proprioception really be improved by exercises? Knee Surg Sports Traumatol Arthrosc, 2001, 9: 128-136. [Medline] [CrossRef]

39) Sefton JM, Yarar C, Hicks-Little CA, et al.: Six weeks of balance training improves sensorimotor function in individuals with chronic ankle instability. J Orthop Sports Phys Ther, 2011, 41: 81-89. [Medline] [CrossRef]

40) Verhagen E, van der Beek A, Twisk J, et al.: The effect of a proprioceptive balance board training program for the prevention of ankle sprains: a prospective controlled trial. Am J Sports Med, 2004, 32: 1385-1393. [Medline] [CrossRef]

41) Hirase T, Inokuchi S, Matsusaka N, et al.: Effects of a balance training program using a foam rubber pad in community-based older adults: a randomized controlled trial. J Geriatr Phys Ther, 2015, 38: 62-70. [Medline] [CrossRef]

42) Lee S, Park J, Lee D: Effects of an exercise program using aero-step equipment on the balance ability of normal adults. J Phys Ther Sci, 2013, 25: 937-940. [Medline] [CrossRef]

43) Shumway-Cook A, Horak FB: Assessing the influence of sensory interaction of balance. Suggestion from the field. Phys Ther, 1986, 66: 1548-1550. [Medline] [CrossRef]

44) Teasdale N, Stelmach GE, Breunig A: Postural sway characteristics of the elderly under normal and altered visual and support surface conditions. J Gerontol, 1991, 46: B238-B244. [Medline] [CrossRef] 